\title{
Von Hippel-Lindau Disease (VHL): A Rare Radiological Case Report
}

\author{
Smrutismita Hota ${ }^{\circledR 1}$, Abdul Faisal ${ }^{2} 2$ \\ ${ }^{1}$ IMS, Department of Radiology, Banaras Hindu University, Varanasi, Uttar Pradesh, India, ²Department of Radiology, Metro Scans and Laboratory, Trivandrum, Kerala, \\ India.
}

\section{Abstract}

Von Hippel-Lindau disease (VHL) is a rare autosomal dominant syndrome caused by mutation in the VHL tumor suppression gene located on chromosome 3. The presented case was a 13 years male patient who initially presented to our hospital with chief complaints of Weakness in b/l lower limbs, Low backache, Right-sided flank pain. On Physical examination there was a lump in right lumbar region- which was firm on palpation. On imaging and histopathology examination the patient was found to have multiple simple pancreatic cysts, malignant renal lesion, retialangioma and spinal hemangioblastoma. So a diagnosis of VHL was made. Regular follow-up with imaging (ultrasound, CT, MRI) are necessary to follow the previous lesions and detect any newly-developed VHL-associate tumors. The Importance of screening is emphasized because the lesions in VHL disease are treatable.

Keywords: Von Hippel-Lindau Disease, Hemangioblastoma, Retialangioma

Corresponding Author: Smrutismita Hota, IMS, Department of Radiology, Banaras Hindu University, Varanasi, Uttar Pradesh, India.

\section{Introduction}

Von Hippel-Lindau disease (VHL) is a rare autosomal dominant syndrome caused by mutation in the VHL tumor suppression gene located on chromosome 3. ${ }^{[1]}$ There is a strong predisposition for tumor development in various organs like pancreatic neuroendocrine tumors, pancreatic cysts (incidence of $35 \%$ to $70 \%$ of patients with VHL), cerebellar and spinal hemangioblastomas (incidence 60-80\%), clear cell renal cell carcinoma (RCC) in $24-45 \%$ of patients, ovarian cysts, and pheochromocytoma. ${ }^{[2-4]}$ Historically, the diagnosis of VHL is made based on the presence of a VHLassociated tumor (retinal or cerebellar hemangioblastoma, pheochromocytoma, or RCC) in a patient with positive family history or 2 tumors in patients without pertinent family history. ${ }^{[4]}$ There is a strong family history in most of the patients. However, about $20 \%$ of patients may have de novo mutation. ${ }^{[5]}$ Here, we present a young patient with multiple simple pancreatic cysts, malignant renal lesion, retialangioma and spinal hemangioblastoma suggestive of a rare sporadic case of VHL.

\section{Case Report}

The presented case was a 13 years male patient who initially presented to our hospital with chief complaints of Weakness in b/l lower limbs, Low backache, Right-sided flank pain. On
Physical examination there was a lump in right lumbar regionwhich was firm on palpation. There was no family history for any genetic disorder. He neither had any history of visual or auditory disturbances nor had any past history of hypertension. There was no evidence of gait disturbance.

USG Abdomen showed large heterogenous solid mass lesion with internal necrotic / cystic areas and vascularity in solid part of the lesion. Also there were multiple simple pancreatic cysts of varying sizes throughout pancreas as on USG. CECT abdomen was performed which showed well defined heterogenously enhancing solid mass lesion with central nonenhancing necrotic areas, arising from upper and mid pole of right kidney and multiple non enhancing cysts of varying sizes throughout Pancreas [Figure 1]. The Contrast enhanced CT Images found homogenously enhancing spinal canal lesion at D10 - D11 Level. MRI Spine T2 Weighted MRI images sagittal section showed relatively defined isointense lesion with internal flow voids in spinal cord at D10-D11 level with long segment hydrosyrinx proximal to the lesion. The lesion shows intense homogenous enhancement on post contrast T1W image confirming its intramedullary location [Figure 2]. On suspicion of VHL disease an Indirect ophthalmoscopy was done which showed right retinal angioma. USG guided FNAC of renal mass was done and histopathological report proved it to be a malignant renal mass. On conglomeration of the above findings, the patient was found to have multiple 


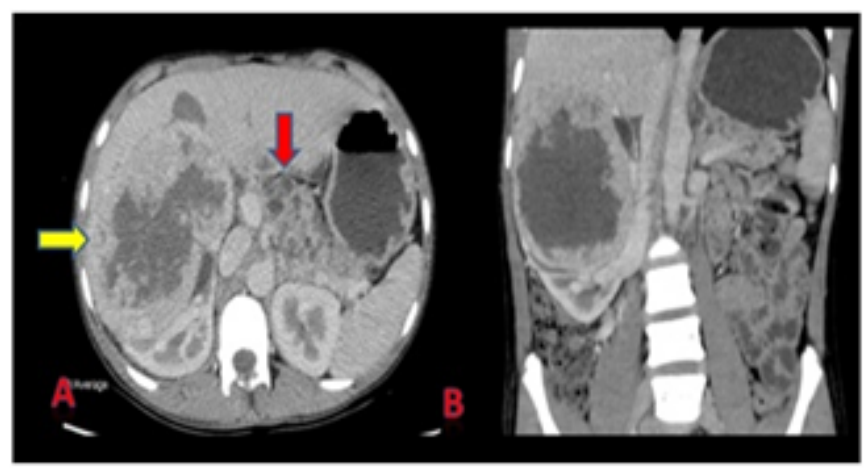

Figure 1: CECT abdomen axial (A) and coronal (B) sections showing well definedheterogenously enhancing solid mass lesion (yellow arrow) with central nonenhancing necrotic areas arising from upper and mid pole of right kidney and multiple non enhancing cysts of varying sizes throughout Pancreas (red arrow).

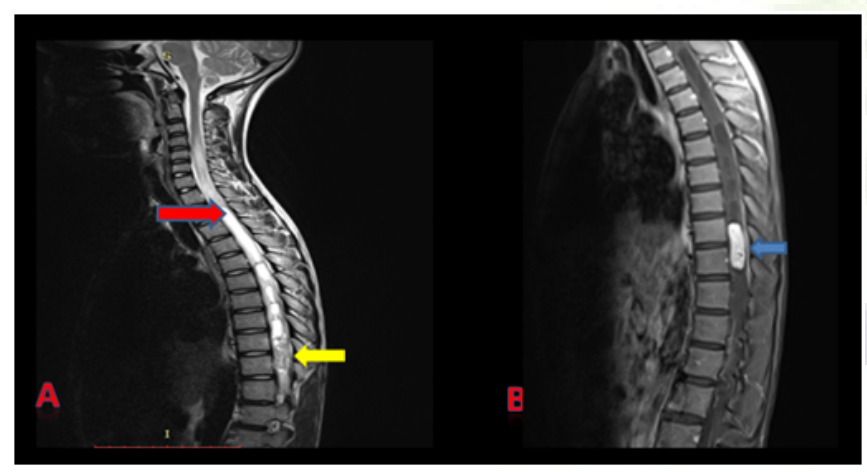

Figure 2: MRI Spine T2 sagittal section(A) showing relatively defined isointense lesion (yellow arrow) with internal flow voids in spinal cord at D10-D11 level with long segment hydrosyrinx ( red arrow)proximal to the lesion. The lesion shows intense homogenous enhancement on post contrast T1W image (B)confirming its intramedullary location (blue arrow) .

simple pancreatic cysts, malignant renal lesion, retialangioma and spinal hemangioblastoma. Hence the case was diagnosed to be VHL.

\section{Discussion}

The prevalence of VHL has been estimated to be between 1:35,000- $1: 40,000 .{ }^{[6,7]}$ The clinical diagnostic criteria for VHL is proposed as:

a. For those with a family history of retinal or central nervous system hemangioblastoma $(\mathrm{Hb})$, only one hemangioblastoma
$(\mathrm{Hb})$ or visceral lesion (renal tumours, pancreatic cysts or tumours, pheochromocytoma, papillary cystadenomas of the epididymis) is required to diagnose VHL . ${ }^{[8,9]}$

b. For isolated cases without a clear family history, two or more hemangioblastoma $(\mathrm{Hb})$ or one hemangioblastoma $(\mathrm{Hb})$ and a visceral manifestation is required for the diagnosis of VHL. ${ }^{[8,9]}$

Central nervous system hemangioblastomas commonly involve cerebellum, spine and medulla Medullaryhemangioblastomas $(\mathrm{MHb})$ occur in about $5 \%$ of VHL patients. ${ }^{[8,10]}$ They are found in postrema of the medulla and may lead to syringobulbia. Unusual sites of hemangioblastomas in VHL include the anterior lobe of the pituitary, pituitary stalk, hypothalamus, optic nerve, corpus callosum, wall of the third ventricle, temporal horn of the lateral ventricles, frontal and temporal lobe and meninges. ${ }^{[8]}$ Spinal hemangioblastomas $(\mathrm{SHb})$ occur in $13-59 \%$ cases. The best imaging technique available for hemangioblastomas is contrast enhanced MRI employing a gadolinium chelate. Routine screening of the CNS in VHL should include, pre and post contrast T1 weighted images of the brain and spinal cord, with thin sections through the posterior fossa and spinal cord and surface coil images of the entire spinal cord. Central nervous system hemangioblastomas commonly contain cystic areas with a solid mural nodule. Small (10 $\mathrm{mm}$ or less) hemangioblastomas are mostly isointense on T1-weighted images and hyperintense on T2-weightedimages showing homogeneous post contrast enhancement. Small hemangioblastomas are located at the surface of the spinal cord while larger ones tend to be hypointense or show mixed signal intensity on T1- weighted images and appear heterogeneous on T2- weighted images. These lesions show heterogeneous post contrast enhancement. A hemangioblastoma larger than $24 \mathrm{~mm}$ is invariably accompanied by vascular flow voids. ${ }^{[11]}$ The solid and contrast-enhancing portions give low signal on diffusion weighted imaging (DWI) with resultant increase in the apparent diffusion coefficient (ADC). These findings indicate rich vascular spaces of the hemangioblastomas which is not seen in the other tumours. DWI may be useful for distinguishing hemangioblastomas from other enhancing cerebellar tumours. ${ }^{[12]}$ Renal cysts are present in 59-63\% of individuals with VHL. Renal cell carcinoma (RCC) develops in $24-45 \%$ of VHL patients. ${ }^{[6,8]}$ Renal involvement in VHL is multicentric and bilateral in at least $75 \%$ of patients. ${ }^{[12]}$ Microscopic solid tumorlets have been identified within the renal parenchyma of patients with VHL. Some of these may develop into macroscopic tumours. Solid tumours have been observed to grow at a mean rate of $1.6 \mathrm{~cm} /$ year which is somewhat faster than those observed in sporadic renal cell carcinoma. ${ }^{[13]}$ Retinal hemangioblastomas $(\mathrm{RHb})$ is seen in $45-59 \%$ of patients with VHL. ${ }^{[7,8]}$ They have been called "retinal angiomas" and "retinal haemangiomas" but hemangioblastoma is the preferred term since they are histologically identical to lesions found in the CNS. In adrenal 
gland involvement, pheochromocytomas tend to occur as a principle manifestation in some families with VHL. Only about $7-18 \%$ of all patients with VHL have pheochromocytomas. ${ }^{\left[{ }^{8,13}\right.}$ Hepatic hemangioblastoma, pulmonary hemangioblastomas, omental cysts, skeletal hemangiomas, ovarian cysts and angiomas, medullary and papillary carcinoma of the thyroid, pituitary adenoma, dermal hemangiomas and pigmented nevi have also been reported to occur with VHL. ${ }^{[9]}$

The renal lesions can be of any type varying from simple cysts, hyperplastic cysts, cysts containing clear cell carcinoma or solid tumors. ${ }^{[13]}$ The full pathologic spectrum may occur in a single kidney. Tumors can arise from a precursor cystic lesion or it can be completely de novo. ${ }^{[14]}$ Thus there is a serious need of serial imaging to detect any malignant transformation of the previously benign cysts. US is useful in distinguishing a solid from a cystic lesion. For detection of small lesions CT is preferred to US. ${ }^{[14]}$ There is little or no wall enhancement for cysts while solid components enhance briskly (50$200 \mathrm{HU}$ ) after administration of contrast material. ${ }^{[15]}$ US is also preferred for surveillance purposes to reduce the amount of radiation exposure to reasonably minimum. For suspicious or equivocal US findings CT should be performed. CT is also useful in cases of multiple renal cysts, where the renal architecture has been distorted and is difficult to analyze with US. ${ }^{[16][M R ~ i m a g i n g ~ i s ~ t h e ~ m o d a l i t y ~ o f ~ c h o i c e ~ f o r ~ s c r e e n i n g ~ o f ~}$ renal lesions in young patients and those with renal failure. The best MR sequences are fast T2- weighted imaging or contrastenhanced T1- weighted imaging with fat suppression. ${ }^{[14,17,18]}$ Simple cysts are hypointense on T1-weighted images and hyperintense on T2-weighted images, with no enhancement after administration of gadolinium contrast material. Complex or solid lesions enhance on postcontrast T1-weighted images and may also demonstrate a low-signal intensity pseudocapsule on T2-weighted images. ${ }^{[18]}$

\section{Conclusion}

The manifestations of VHL disease are protean. In spite of the availability of genetic testing imaging plays a key role in the identification of abnormalities, in the screening of asymptomatic gene carriers and in their long-term surveillance. Regular follow-up with imaging (ultrasound, CT, MRI) are also necessary to follow the previous lesions and detect any newlydeveloped VHL-associate tumors. Importance of screening lies in the fact that the lesions in VHL disease are treatable. Early detection helps to adopt the more conservative form of therapy and prolongs quality of life of the patient.

\section{References}

1. Keutgen XM, Hammel P, Choyke PL, Libutti SK, Jonasch E, Kebebew E. Evaluation and management of pancreatic lesions in patients with von Hippel-Lindau disease. Nat Rev Clin
Oncol. 2016;13(9):537-549. Available from: https://dx.doi. org/10.1038/nrclinonc.2016.37.

2. Sharma A, Mukewar S, Vege SS. Clinical Profile of Pancreatic Cystic Lesions in von Hippel-Lindau Disease. Pancreas. 2017;46(7):948-952. Available from: https://dx.doi.org/10. 1097/mpa.0000000000000875.

3. Ayloo S, Molinari M. Pancreatic manifestations in von HippelLindau disease: A case report. Int J Surg Case Rep. 2016;21:7072. Available from: https://dx.doi.org/10.1016/j.ijscr.2016.02. 031 .

4. Dutta D, Bhuyan M, Baishya B, Hussain Z. Cerebellospinal hemangioblastoma with bilateral pheochromocytoma and hepatic cyst: A rare entity. Asian J Neurosurg. 2016;11(3):311312. Available from: https://dx.doi.org/10.4103/1793-5482. 179644.

5. Maher ER, Neumann HP, Richard S. von Hippel-Lindau disease: A clinical and scientific review. Eur J Hum Genet. 2011;19(6):617-640. Available from: https://dx.doi.org/10. 1038/ejhg.2010.175.

6. Maher ER, Iselius L, Yates J. Von Hippel-Lindau disease: a genetic study. J Med Genet. 1991;28(7):443-447. Available from: http://dx.doi.org/10.1136/jmg.28.7.443.

7. Neumann HPH, Wiestler OD. Clustering of features of von Hippel-Lindau syndrome: evidence for a complex genetic locus. Lancet. 1991;337(8749):1052-1054. Available from: https://dx.doi.org/10.1016/0140-6736(91)91705-y.

8. Maher ER, J R Yates RH, Benjamin C, Harris R, Moore AT, Ferguson-Smith MA. Clinical Features and Natural History of von Hippel-Lindau Disease. Q J Med. 1990;77(283):11511163. Available from: https://dx.doi.org/10.1093/qjmed/77.2. 1151.

9. Melmon KL, Rosen SW. Lindau's Disease. Review of the Literature and Study of a Large Kindred. Am J Med. 1964;36:595-617. Available from: https://doi.org/10.1016/ 0002-9343(64)90107-x.

10. Lodrini S, Lasio G, Cimino C, Pluchino F. Hemangioblastomas: Clinical characteristics, surgical results and immunehistochemical studies. J NeuroSci. 1991;35(4):179-185.

11. Chu BC, Satoshi T, Hida K, Furukawa M, Abe S, Miyasaka K. MR findings in Spinal Hemangioblastoma: Correlation with symptoms and with angiographic and surgical findings. Am J Neuroradiol. 2001;22(1):206-223.

12. Quadery FA, Okamoto K. Diffusion-weighted MRI of haemangioblastomas and other cerebellar tumours. Neuroradiology. 2003;45(4):212-219. Available from: https://dx.doi.org/ 10.1007/s00234-003-0951-y.

13. Choyke PL, Glenn GM, Walther MM, Zbar B, Weiss GH, Alexander RB, et al. The natural history of renal lesions in von Hippel-Lindau disease: a serial CT study in 28 patients. AJR Am. 1992;159(6):1229-1234. Available from: https://dx.doi. org/10.2214/ajr.159.6.1442389.

14. Choyke PL, Glenn GM, Walther MM, Patronas NJ, Linehan WM, Zbar B. von Hippel-Lindau disease: genetic, clinical, and imaging features. Radiology. 1995;194(3):629-642. Available from: https://dx.doi.org/10.1148/radiology.194.3.7862955.

15. Choyke PL, Glenn GM, Walther MM, Zbar B, Linehan WM. Hereditary Renal Cancers. Radiology. 2003;226(1):33-46. Available from: https://dx.doi.org/10.1148/radiol.2261011296. 
16. Levine E, Lee KR, Weigel JW, Farber B. Computed Tomography in the Diagnosis of Renal Carcinoma Complicating HippelLindau Syndrome. Radiology. 1979;130(3):703-706. Available from: https://dx.doi.org/10.1148/130.3.703.

17. Taouli B, Ghouadni M, Corréas JM, Hammel P, Couvelard A, Richard S, et al. Spectrum of Abdominal Imaging Findings in von Hippel-Lindau Disease. AJR Am. 2003;181(4):10491054. Available from: https://dx.doi.org/10.2214/ajr.181.4. 1811049.

18. Hes FJ, Feldberg MAM. Von Hippel-Lindau disease: strategies in early detection (renal-, adrenal-, pancreatic masses). Eur Radiology. 1999;9(4):598-610. Available from: https://dx.doi. org/10.1007/s003300050717.
Copyright: (C) the author(s), 2020. It is an open-access article distributed under the terms of the Creative Commons Attribution License (CC BY 4.0), which permits authors to retain ownership of the copyright for their content, and allow anyone to download, reuse, reprint, modify, distribute and/or copy the content as long as the original authors and source are cited.

How to cite this article: Hota S, Faisal A. Von Hippel-Lindau Disease (VHL): A Rare Radiological Case Report. Asian J. Med. Radiol. Res. 2020;8(1):36-39.

DOI: dx.doi.org/10.47009/ajmrr.2020.8.1.7

Source of Support: Nil, Conflict of Interest: None declared. 